\title{
THE PROGNOSTIC VALUE OF CATASTROPHIZING FOR PREDICTING THE CLINICAL EVOLUTION OF LOW BACK PAIN PATIENTS. A study in routine clinical practice within the Spanish National Health Service [NCT00502333].
}

Francisco M. Kovacs, MD, PhD, ${ }^{1,2}$ Jesús Seco, MD, PhD, ${ }^{3,2}$ Ana Royuela, MSc, ${ }^{4,5,2}$ Josep Corcoll,MD, ${ }^{6,2}$ Andrés Peña, MD, PhD, ${ }^{7,2}$ and the Spanish Back Pain Research Network ${ }^{+}$

1: Fundación Kovacs, Palma de Mallorca, Spain.

2: Spanish Back Pain Research Network.

3: Departamento de Enfermería y Fisioterapia. Instituto de Biomedicina. Universidad de León, Ponferrada, Spain.

4: CIBER Epidemiología y Salud Pública (CIBERESP). Spain.

5: Unidad de Bioestadística Clínica. Hospital Ramón y Cajal, IRYCIS, Madrid. Spain.

6: Centro de Salud de Tramuntana-Esporlas, Mallorca, Spain.

7: Servicio de Rehabilitación. Hospital Ramón y Cajal. Madrid, Spain.

${ }^{+}$: Other members of the Spanish Back Pain Research Network who authored this study are: Alfonso Muriel, MSc, ${ }^{4,5,2}$ Víctor Abraira, ${ }^{4,5,2}$ María Nieves Plana, ${ }^{4,5,2}$ Antonio Pallicer, Centro de Salud Santa Eulalia, Ibiza, Mario Gestoso, ${ }^{1}$ Nicole Mufraggi, ${ }^{1}$ Carlos Isanta, Centro de Salud San José Norte, Zaragoza, Monserrat Núñez, Hospital Clínic, Barcelona, José Luis Peña Sagredo, Hospital Universitario Marqués de Valdecilla, Santander, Pilar Brieva, Hospital Universitario Marqués de Valdecilla, Santander, Luis Alvarez Galovich, Fundación Jiménez Díaz, Madrid, Salvador Fuster, Hospital Clínic, Barcelona, Javier Zamora, ,5,2 Francisco Javier Cano-García, Departamento de Personalidad, Evaluación y Tratamiento Psicológicos, Universidad de Sevilla, Daniel Benítez Melero, Centro de Salud de Montequinto, Sevilla, Francisco Martínez, Centro de Salud Bembibre, León, Elena Rodríguez, Unidad Básica Bahía Grand, Lluchmajor, Baleares, Rosa Vecino Lafort, Centro de Salud San José Norte, Zaragoza, Dolores Vázquez, Mutua Asepeyo, Madrid, Mariano Ortega, Centro de Salud Es Trencadors, Lluchmayor, Baleares, Jenny Moix, Departamento de Psicología Básica, Evolutiva y de la Educación, Universidad Autónoma de Barcelona, Bellaterra, Spain, Eva Allvé, Centro de Salud San José Norte, Zaragoza, Teresa LópezMelus, Centro de Salud San José Norte, Zaragoza, Patricia Gracia, Centro de Salud San José Norte, Zaragoza, $\mathrm{M}^{\mathrm{a}}$ Dolores Vicente, Centro de Salud San José Norte, Zaragoza, $\mathrm{M}^{\mathrm{a}}$ Ángeles Gay, Centro de Salud San José Norte, Zaragoza, Isabel Torres, Centro de Salud San José Norte, Zaragoza, Pilar Borraz, Centro de Salud San José Norte, Zaragoza, Emilio Suárez Sánchez, Centro de Salud de Montequinto, Sevilla, Ana Expósito, Centro de Salud San José Norte, Zaragoza, Ana Hernández, Centro de Salud San José Norte, Zaragoza, Gloria Sanz, Centro de Salud San José Norte, Zaragoza, Yolanda Sánchez, Centro de Salud San José Norte, Zaragoza, Pilar Melón Juncosa, Centro de Salud San José Norte, Zaragoza, Mireia Barceló Castelló, Centro de Salud San José Norte, Zaragoza, Milagros Buero Gallego, Departamento de Personalidad, Evaluación y Tratamiento Psicológicos, Universidad de Sevilla, José Sánchez Blanco, Distrito Sanitario Sevilla Sur

Corresponding author: Francisco M. Kovacs, MD, PhD. Departamento Científico, Fundación Kovacs, Paseo de Mallorca 36, 07012 Palma de Mallorca, Spain. Tel: +34 971 720809; Fax: +34 971 720774; kovacs@kovacs.org.

All the authors contributed substantially to the conception and design of this study, and to the revision of this article, take public responsibility for the appropriateness of the design and method, and the collection, analysis and interpretation of the data. All the authors have reviewed and approved the final version of this manuscript for submission and/or publication.

Francisco Kovacs, Jesús Seco, Ana Royuela and Josep Corcoll designed the forms used to collect the data, and the database in which they were introduced for analysis. Francisco 
Kovacs, Jesús Seco, Josep Corcoll, Antonio Pallicer, Mario Gestoso, Nicole Mufraggi, Carlos Isanta, Monserrat Núñez, José Luis Peña Sagredo, Pilar Brieva, Luis Alvarez Galovich, Salvador Fuster, Daniel Benítez Melero, Francisco Martínez, Elena Rodríguez, Rosa Vecino Lafort, Dolores Vázquez, Mariano Ortega, Eva Allvé, Teresa López-Melus, Patricia Gracia, $\mathbf{M}^{\mathrm{a}}$ Dolores Vicente, $\mathrm{M}^{\mathrm{a}}$ Ángeles Gay, Isabel Torres, Pilar Borraz, Emilio Suárez Sánchez, Ana Expósito, Ana Hernández, Gloria Sanz, Yolanda Sánchez, Pilar Melón Juncosa, Mireia Barceló Castelló, José Sánchez Blanco screened their patients, recruited those complying with inclusion criteria and gathered data from their assessments. Francisco Kovacs, Francisco Javier Cano-García, Jenny Moix and Milagros Buero Gallego, ensured that data included in the database were consistent with those included in the forms filled by the patients. Ana Royuela, Víctor Abraira, María Nieves Plana, Alfonso Muriel and Javier Zamora analyzed the data. Francisco M. Kovacs and Ana Royuela take responsability for the accuracy of data anlaysis. Francisco M. Kovacs wrote this manuscript, had full access to all of the data in the study, and takes full responsibility for the integrity of the data and the decision to submit it for publication.

Acknolwedgements: This study was jointly funded by the Spanish Ministry of Health's Agency for Quality and the Kovacs Foundation, a Spanish not for profit Institution with no links to the health industry. The funding institutions had no role in the design and conduct of the study; data collection; management, analysis and interpretation of the data; preparation, review and approval of the manuscript; or the decision to submit the article for publication.

No benefits in any form have been or will be received from a commercial party related directly or indirectly to the subject of this article. The authors do not have conflicts of interest to report. 


\begin{abstract}
Background/context: Experimental studies suggest that catastrophizing may worsen the prognosis of low back pain (LBP) and LBP-related disability, and increase the risk of chronicity.
\end{abstract}

Purpose: To assess: a) The prognostic value of baseline catastrophizing for predicting the clinical evolution of LBP patients in routine clinical practice b) The association between the evolution of pain and catastrophizing.

Study design/setting: Prospective study in routine clinical practice of the Spanish National Health Service.

Patient sample: 1,422 acute and chronic adult LBP patients treated in primary and hospital care.

Outcome measures: pain, disability and catastrophizing, measured through validated instruments.

Methods: Patients were managed according to routine clinical practice. Outcome measures were assessed at baseline and 3 months later. Logistic regression models were developed to estimate the association between baseline catastrophizing score and the improvement of LBP and disability, adjusting for baseline LBP and leg pain severity, disability, duration of the pain episode, workers' compensation coverage, radiological findings, failed back surgery, diagnostic procedures and treatments undertaken throughout the study. Another model was developed to estimate the association between the evolution of LBP and the change in catastrophizing, adjusting for the same possible confounders plus the evolution of leg pain and disability. Models were repeated excluding the treatments undergone after the baseline assessment.

Results: Regression models showed that the degree of baseline catastrophizing does not predict the evolution of LBP and disability. Conversely, as the degree of pain improvement increases, so does the OR for improvement in catastrophizing, ranging from 3 (CI 95\% 2.00; 4.50, $\mathrm{p}<0.001$ ) for improvements in pain between 1.1 and 4 VAS points, to 7.3 (CI $95 \% 3.49 ; 15.36, \mathrm{p}<0.001$ ) for improvements in pain $>6.1$. Similar results were obtained when treatments were excluded from the models.

Conclusions. In routine practice, assessing the baseline score for catastrophizing does not help clinicians to predict the evolution of LBP and disability at 3 months.

Key words: Low back pain, disability, prediction, catastrophizing, routine clinical practice. 


\section{Introduction}

Nonspecific or common low back pain (LBP) is defined as pain between the costal margins and the inferior gluteal folds, which may be associated with pain referred down to the leg ("leg pain"), and is usually accompanied by painful limitation of movement. Diagnosing common LBP implies that the pain is not related to conditions such as fractures, spondylitis, direct trauma, or neoplastic, infectious, vascular, metabolic, or endocrine-related processes. ${ }^{1}$

Two of the main psychological factors which have been considered to negatively influence the prognosis of pain and disability in LBP patients, are fear-avoidance beliefs (FAB) and catastrophizing. ${ }^{1-9}$ FAB refer to the fear-induced avoidance of movements or activities which are expected to be painful, whereas catastrophizing is defined as an exaggerated negative mental state related to an actual or anticipated painful experience. ${ }^{1-9}$ In the Spanish cultural environment, FAB have shown to have an either negligible or nonexistent influence on LBP among elderly populations and among acute, subacute and chronic LBP patients treated in routine practice, ${ }^{10-13}$ whereas catastrophizing correlates with disability and explains approximately one fourth of its variance, ${ }^{13,14}$ suggesting that it may have an influence on the prognosis of LBP patients.

From a theoretical point of view, pre-existing catastrophizing thoughts may hamper patients' clinical evolution. Conversely, it could also be hypothesized that catastrophizing would appear or be reinforced in patients who experience a disappointing clinical evolution, successive failed treatments and continued pain and disability. This poses a "chicken and egg" dilemma, on the potential reciprocal influence between catastrophizing and lack of clinical improvement. ${ }^{3,7-9}$

In fact, previous cross-sectional studies have shown that catastrophizing, pain and disability correlate with each other, ${ }^{13-18}$ but results from prospective studies are inconsistent. Some randomized controlled trials and small studies in routine practice suggest that baseline catastrophizing is associated with the evolution of pain and disability, some suggest the contrary, and others conclude that catastrophizing predicts the outcome of acute LBP, but not before 6 weeks after the onset of pain., ${ }^{2,4,79-31}$ Results from the only large prospective study conducted in routine practice, suggest that baseline catastrophizing does not predict the evolution of LBP-related disability. ${ }^{32}$

If catastrophizing were to actually have a negative influence on prognosis, it would follow that, in routine practice, clinicians should identify patients in whom psychological treatment to address catastrophizing should be considered. To this end, a cut-off value for baseline catastrophizing, above which reducing it would be required to treat LBP successfully, should be identified.

Therefore, the objectives of this study were to: a) Determine whether assessing baseline catastrophizing would help clinicians to predict the clinical evolution of low back pain patients, in routine clinical practice, while establishing the cut-off point to identify subjects in whom catastrophizing may hinder recovery and should therefore be treated, b) Assess the association between improvement in pain and the evolution of catastrophizing.

\section{Methods}


$\underline{\text { Setting }}$

This study was performed in 14 Health Care Centers from 7 different regions in Spain. Twelve belonged to the Spanish National Health Service (SNHS), and 2 to not-for-profit Foundations working for the SNHS.

Participating centers included 6 primary care centers and 8 specialty centers in rehabilitation, neuroreflexotherapy, orthopedic surgery, and rheumatology.

\section{$\underline{\text { Subjects }}$}

Inclusion criteria were: seeking care in a participating center for LBP with or without leg pain, not caused by direct trauma or systemic diseases, not complying with criteria for referral to surgery, and being able to read in Spanish.

Pain not caused by systemic diseases was defined as pain in patients who had not been diagnosed with cancer, fibromyalgia or inflammatory diseases, such as rheumatoid arthritis or Bechterew's disease (Ankylosing Spondylitis), and who did not show signs suggesting fibromyalgia or "red flags" for potential underlying systemic diseases.

"Signs suggesting fibromyalgia" were defined as diffuse pain with unexplained fatigue or sleep disturbances, and "red flags" for potential underlying systemic diseases were defined as oncologic disease during the previous 5 years, constitutional symptoms (unexplained weight loss, fever, chills), history of intravenous drug use, or immunocompromised host. ${ }^{1,33-35}$

Criteria for referral to surgery were defined as signs suggesting cauda equina syndrome, or nerve root compression due to disk herniation or spinal stenosis potentially qualifying for surgery. Relevant or progressive paresia, loss of sphincter control or saddle anesthesia, were considered as signs suggesting cauda equina syndrome. Potential surgical criteria for disk herniation were defined as disabling sciatic pain lasting 6 weeks or more, caused by a compromised nerve root demonstrated by magnetic resonance (MRI). Potential surgical criteria for symptomatic lumbar spinal stenosis were defined as radicular pain lasting 3 or more months, or claudication unrelated to peripheral vascular disease, with evidence of stenosis on MRI or CT scans. ${ }^{1}$

Patients who had undergone unsuccessful spine surgery ("failed back surgery") and those with "red flags" in which appropriate test procedures had ruled out systemic diseases, were invited to participate in the study.

Exclusion criteria were: treated or untreated central nervous system impairment, refusal to sign the informed consent, and leaving a questionnaire assessing any of the variables unanswered.

The design of this study did not imply any variation in the patients' clinical management. Therefore, as opposed to randomized clinical trials, there were no ethical reasons for keeping the sample size as small as possible. As a result, sample size for this study was established at 1,500, in order to ensure enough statistical power, given that: a) previous studies had suggested that the potential effect of catastrophizing in Spanish 
subjects could be small, ${ }^{10,11,16}$ b) approximately $80 \%$ of LBP patients treated in routine practice within the Spanish National Health Service, report a clinically relevant improvement at 3 months, ${ }^{36,37}$ and previous studies have shown that improvements are not normally distributed, ${ }^{36,38}$ which excludes linear regression analysis and implies the need to dichotomize continuous variables for logistic regression analyses, which in turn may reduce statistical power, d) this sample size would allow the introduction of up to 30 variables in the regression models as potential confounders. ${ }^{39}$

\section{Procedure}

The study protocol was approved by the Ethical Committees of the participating Hospitals and institutions.

All patients seeking care for LBP who were treated by physicians participating in this study, were screened for inclusion and exclusion criteria. The physicians explained the study's characteristics to eligible patients, as well as how important it was for them to fully and accurately answer the questionnaires. They finally invited patients to sign the corresponding informed consent. The patients who signed it were included in the study. Neither patients nor recruiting physicians received any compensation for their participation in this study.

Patients were assessed upon recruitment and three months later. At both assessments, patients completed all the self-administered questionnaires by themselves, in private. The only instructions they received, were those included in the standard validated versions of the self-administered questionnaires. They received no help or further directions from health care personnel, research staff or other third parties. Once completed, the questionnaires were collected by auxiliary personnel not related to the study. Data were introduced into a database at a central coordination office by two administrative assistants, who double-checked that the data introduced coincided with ratings on the questionnaires.

Following routine practice conditions, all decisions on clinical management, including the prescription of any kind of diagnostic tests or treatments, were left up to the treating clinicians, and no measures were taken to homogenize their criteria. Clinicians had access to the scores for pain and disability, since these data can influence their clinical recommendations, but not to the score for catastrophizing.

\section{$\underline{\text { Variables }}$}

At the first assessment, patients were asked to complete questionnaires gathering data on gender, age (date of birth), duration of current pain episode (days), and working status (classified as "not eligible"-i.e. students, housewives, unemployed, retired-, or "eligible for worker's compensation benefits", which in Spain can represent up to $100 \%$ of the salary irrespective of whether the worker is working or not -i.e., working, on sick leave or disabled-).

In this study, LBP and leg pain severity, and LBP-related disability were considered the main indicators of patients' clinical evolution. ${ }^{40}$ At both assessments, patients were asked to rate the intensity of low back pain (LBP), leg pain (LP), LBP-related disability, and catastrophizing. Pain intensity was measured with a $10-\mathrm{cm}$ visual analog scale (VAS, for 
which $0=$ no pain and $10=$ worst possible pain $).{ }^{41}$ Low back pain-related functional disability was measured using the validated Spanish version of the Roland-Morris questionnaire (RMQ), ${ }^{42}$ in which disability is scored from 0 to 24 points (better to worse). Catastrophizing was measured using the catastrophizing subscale of the validated Spanish version of the Coping Strategies Questionnaire, in which patients' use of catastrophizing strategies to cope with pain is scored from 0 (no use) to 36 (maximum possible use of those strategies). ${ }^{43}$

Recruiting physicians provided data on patients' radiological findings (no findings, disc degeneration, scoliosis, spondylolisthesis, spondylolysis, annular tear, disc protrusion, disc herniation, $>1 \mathrm{~cm}$. difference in leg length, lumbarization of S1, sacralization of L5, other radiological findings), and history of failed back surgery related to current episode (yes/no), as well as diagnostic procedures (X-Rays, scanner, MRI, EMG, blood analyses, scintigraphy, other) and treatments which the patient had undergone throughout the study (drugs -NSAIDs, muscle relaxants, other drugs-, physiotherapy or rehabilitation, neuroreflexotherapy (NRT) intervention, surgery, other treatments).

\section{$\underline{\text { Analysis }}$}

Absolute and relative frequencies were calculated for categorical variables, and mean and standard deviation (SD) for continuous ones. The characteristics of the patients who improved and did not improve were compared using the Mann-Whitney test for continuous variables. Categorical variables were compared through the chi-squared test, or the Fisher's exact probability test when chi-squared was not applicable.

Improvements in pain and disability were defined as any reduction in the score of VAS or RMQ being higher than the minimal clinically important change (MCIC). Previous studies have established MCIC for pain and disability at 30\% of their baseline score, with a minimum value of 1.5 for VAS and 2.5 for RMQ. ${ }^{37}$ RMQ cannot be scored with decimals so, in this study, improvement was defined as "clinically relevant" when $\geq 1.5$ VAS points or $\geq 3$ RMQ points. Similarly, a "relevant reduction" in the CSQ score was defined as any reduction $\geq 30 \%$ of its baseline value. ${ }^{37,44}$ Since no data on MCIC for CSQ are available, a sensitivity analysis was conducted in which "change in the CSQ score" was defined as any positive difference between assessments at baseline and 3 months. According to these definitions, improvement was impossible when baseline scores were $\leq 1,5$ VAS points for pain, $\leq 3 \mathrm{RMQ}$ points for disability, or $\leq 1 \mathrm{CSQ}$ point for catastrophizing. Therefore, patients with such a baseline score for a given variable, were excluded from the analysis which focused on the improvement of that variable.

Two logistic regression models were developed to estimate the association between baseline CSQ score and the improvement of LBP and LBP-related disability during the study period, adjusting for other possible confounders. In order to relax the assumption of linearity among dependent variables and baseline CSQ, baseline CSQ score was categorized in quartiles and introduced into the models as dummy variables, using the first quartile as the reference one.

At the design phase of this study, it was decided that all recorded variables that might exert an influence on the evolution of pain and disability, would be included as potential confounders in the models. These included gender, age (in years), baseline values for LBP (VAS points), leg pain (VAS points) and LBP-related disability (RMQ points), duration of 
the current episode (collected in days and classified as acute -less than 14 days-, subacute -14 to 90 days-, chronic -91 to 365 days- and extremely chronic -over 365 days-), ${ }^{38,45}$ workers' compensation coverage, diagnosis of “failed back surgery", radiological findings (disc degeneration, spondylolisthesis/spondylolysis, spinal stenosis, disc protrusion/hernia, no findings), diagnostic procedures performed throughout the study (X-Rays, MRI, CT scan, scintigraphy, electromyography, blood analysis), and treatments received before and during the study (NSAIDs, steroids, muscle relaxants, other drugs, physiotherapy, rehabilitation, NRT intervention, or surgery). In order to assess whether chronicity modified the association between baseline CSQ score and the evolution of pain and disability, the interaction between baseline CSQ score and chronicity was also included in the maximal model. CSQ was forced into a non-automatic backward elimination strategy oriented at providing a valid estimate, so that the variable with the highest $\mathrm{P}$ value that was not a confounder was excluded at every step. ${ }^{46,47}$ Variables were considered to be confounders if the estimate of the coefficient of CSQ changed by more than $10 \%$ when that variable was removed from the maximal model. In order to avoid the loss of statistical power, independent continuous variables were not categorized. ${ }^{48}$

It was hypothesized that, although clinicians did not have access to patients' baseline CSQ scores, the degree of baseline catastrophizing might have been linked to some patients' characteristics which, in turn, could have influenced clinicians' decisions with regards to treatment. Therefore, analyses were repeated excluding treatments received during the follow-up period.

Another logistic regression model was developed to estimate the association between the evolution of LBP (categorized in quartiles and introduced in the model as dummy variables), and the change in CSQ (defined as any change in the score being $\geq 30 \%$ of baseline value), adjusting for other possible confounders. In addition to all the potential confounders listed in the models described above, the maximal model also included the evolution of LP and disability. Evolution of LBP, LP and disability was defined as the baseline score minus the final one, so that positive values reflect improvement. Criteria used to consider a variable as a confounder were the same as described above.

To validate these three models, the sample was randomly split into two sub-samples for each model. The first one (training sample) included $80 \%$ of patients. The second one (validation sample), included the remaining patients (i.e., 20\%). ${ }^{47}$ Collinearity of the maximal model in training samples was evaluated using the criteria proposed by Belsley. ${ }^{49}$

The SPSS v17 (SPSS Inc, Chicago, IL) was used for statistical analysis.

\section{Results}

Thirty three clinicians screened 1,565 patients. Sixty-five patients declined to commit to the follow-up visit and did not sign the informed consent. The remaining 1,500 (95.67\%) patients were included. There were no losses to follow-up, but 78 subjects (5.2\%) were excluded at the analysis phase for having left questionnaires on LBP (32 patients), LP (47), disability (39), catastrophizing (34), or workers' compensation coverage (4), unanswered. Sixty-two out of those 78 patients left two or more questionnaires unanswered. Therefore, 1,422 patients were included in the analysis. Their mean age was 52.6 years, and most were women (62.6\%) with chronic LBP (58.4\%). At baseline, their mean CSQ score was 
15 points, although 143 patients (10.1\%) had a CSQ score over $75 \%$ of the maximum possible. Patients' baseline characteristics are shown in Table 1.

At baseline, 24 patients had a pain score $\leq 1,5$ VAS points, 77 had a disability score $\leq 3$ RMQ points, and 6 had a score on the CSQ $\leq 1$. Therefore, they were excluded from the analysis focusing on the improvement of the corresponding variable (Table 2). Pain worsened in only 36 patients (2.5\% of the sample), disability in 40 (2.8\%) and catastrophizing in 91 (6.4\%). Therefore, no separate analyses were made for these patients and they were included in the "did not improve" category for the corresponding variable.

There were some differences between patients who experienced improvements in pain, disability and catastrophizing, and those who did not (Table 2). Among patients who improved, failed back surgery was less common, diagnostic procedures were less frequently performed, and the treatments prescribed differed from those undergone by patients who did not improve. In addition, among the 1,043 patients in whom pain improved throughout the study period, baseline pain severity was higher, fewer were chronic, and fewer showed disk protrusion or hernia on MRI. Among the 879 in whom disability improved, baseline RMQ scores were higher and fewer showed no radiological findings in imaging. Among the 1,010 in whom catastrophizing improved, baseline CSQ scores were higher, leg pain was more common, and fewer showed no radiological findings in imaging (Table 2).

The model analyzing the association between baseline catastrophizing and the evolution of low back pain had to be adjusted by baseline severity of low back pain, baseline degree of disability, and whether the patient received NRT intervention. The training sample included 1,103 patients, and the validation one, 295. There were no collinearity problems. No association was found between baseline CSQ score and the evolution of LBP (Table 3). This was the case for both the training and validation samples. When treatments were removed from the model, changes in results were minor (Table 3).

The model analyzing the association between baseline catastrophizing and the evolution of disability, had to be adjusted by baseline score for disability, and whether the patient received NRT intervention. The training sample included 1,088 patients, and the validation one, 257. There were no collinearity problems. No association was found between baseline CSQ and the evolution of disability (Table 4). This was the case for both the training and validation samples. When treatments were removed from the model, changes in results were minor (Table 4).

The last regression model showed that the evolution of catastrophizing throughout the study period was associated with the evolution of LBP (Table 5). The training sample included 1,124 patients and the validation one, 292. As the degree of pain improvement increased, so did the OR for improvement in catastrophizing, ranging from 3 (CI 95\% 2.00; 4.50, $\mathrm{p}<0.001$ ) for improvements in pain between 1.1 and 4 VAS points, to 7.3 (CI $95 \% 3.49$; 15.36, $\mathrm{p}<0.001$ ) for improvements in pain $>6.1$ VAS points (Table 5). The ORs (95\% CI) in the validation sample were similar to the ones found in the training sample (data not shown). When treatments were removed from the model, changes in results were minor (Table 5). There were no collinearity problems. In the sensitivity analysis in which "change" in the CSQ score was defined as "any change", instead of a variation $\geq 30 \%$ of its baseline score, the results were virtually identical (Table 5). 
Among the 34 patients who left the CSQ unanswered at the follow-up assessment, 27 had answered it at the baseline assessment and their median (IQR) score was $7(2,11)$. The baseline CSQ score was unknown for only 7 patients $(0.5 \%)$. Therefore, it was decided not to perform a sensitivity analysis.

\section{Discussion}

Results from this study show that baseline catastrophizing is of no clinical value for predicting the evolution of low back pain (LBP) and disability. Hence, it is not appropriate to use catastrophizing for early identification of those patients with a bad clinical prognosis.

“Association” is different from "causality”. Therefore, results from this study might be interpreted as suggesting that improvement in pain leads to improvement in catastrophizing, or viceversa. However, from both a psychological and a biological perspective, it is more likely that catastrophizing may appear or worsen when pain does not improve despite treatments received. The fact that the baseline degree of catastrophizing does not predict the evolution of pain and disability (Tables 3 and 4), further supports this interpretation. However, it might be argued that, in patients with a higher degree of catastrophizing, pain needs to improve further before they notice any improvement, and that the placebo effect may be smaller or shorter. Therefore, further studies should assess the potential influence of catastrophizing on the minimal clinically important change for pain and disability, and on the size and duration of the placebo effect.

These results suggest that the correlation previously found between catastrophizing, LBP and LBP-related disability in cross-sectional studies, ${ }^{13-18}$ may be of little practical clinical value, since it might be explained by the fact that the OR for improvement in catastrophizing increases with pain improvement (Table 5). Results from a study conducted in the same cultural setting, showed that the correlation of catastrophizing and other psychological variables with disability, ceases to be significant when variations of trait anxiety are taken into account, suggesting that other psychological variables may play a more relevant role than catastrophizing. ${ }^{50}$ This is also consistent with results from a large study conducted in routine practice in the Anglo-Saxon cultural context, which showed that among 20 potential psychological obstacles to recovery, only 4 (including neither FAB nor catastrophizing) were predictive of the clinical evolution of disability. ${ }^{32}$ Results from randomized controlled trials and small prospective studies are inconsistent. $2,4,7,12,18-31$ Differences in sample size, recruitment context (e.g., patients treated in routine practice vs. secondary analyses of data gathered in clinical trials), patients' characteristics, and statistical methods used across studies (e.g., use of hierarchical vs. non-hierarchical models) can account for this inconsistency. For instance, the use of hierarchical models implies pre-hoc assumptions and favors those variables which the authors choose to enter first, since these have a greater chance of attaining statistical significance.

It seems theoretically plausible that catastrophizing may be influenced by the duration of pain, the radiological findings (and potential explanations given to the patients with regards to it), and having undergone aggressive treatments. However, in this study catastrophizing scores were not influenced by these variables. In fact, the association between pain improvement and catastrophizing was the same among acute and chronic patients, and the prognostic value of baseline catastrophizing for predicting the clinical 
evolution was null among both acute and chronic patients (Tables 3-5). Results from the logistic regression models showed that the only relevant feature with respect to the evolution of catastrophizing, is whether pain severity improves (Table 5). This might be interpreted as suggesting that patients do not tend to catastrophize if pain severity is improving, independently of its duration.

The objective of this study was to appraise the usefulness of assessing catastrophizing in the management of LBP patients in routine clinical practice. As a result, all kinds of LBP patients were included in this study; acute and chronic, with and without leg pain, having undergone unsuccessful spine surgery or not, etc. However, regression models show that none of these characteristics influence the null prognostic value of baseline catastrophizing for predicting patients' clinical evolution. At the design phase it was also decided that this study should be conducted in conditions as close as possible to routine practice in the Spanish National Health Service (SNHS). As a result, patients were managed as they usually are in routine practice, and clinical decisions were left up to the treating physician. However, LBP-related clinical practice is roughly consistent within the SNHS, and it generally follows current evidence-based guidelines. ${ }^{36,51,52}$ The seven Spanish regions in which this study was conducted represent most of the economic and cultural spectrum of the country. Acute (41.9\%) and chronic (58.1\%) patients were recruited in routine clinical practice, in primary and specialty centers belonging to or working for the SNHS. The SNHS is a tax-funded public organization in which all health care services are provided free to every resident in Spain (except aesthetic surgery and some dental procedures). ${ }^{36}$ Only a small minority of patients in the upper economic class seek health care exclusively through private health care. Low rates of included patients among those screened, losses to follow-up and missing data, may introduce a risk of bias. In this study, over $95 \%$ of the patients screened were included, there were no losses to follow-up, and only 78 out of 1,500 patients (5.2\%) were excluded from the analysis due to missing data. All these features suggest that generalizability of these results to LBP patients treated within the SNHS should not be a concern.

It has been suggested that the role of psychological variables in the evolution of LBP, may vary across cultural contexts. In fact, while associations between LBP and catastrophizing have been observed in some studies conducted in the Northern European and Anglo-Saxon cultural contexts..$^{2-4,7,20-31,53-56}$, to date no psychological variable has shown to be relevant with regards to the treatment or clinical evolution of LBP patients in the Spanish context. ${ }^{11-}$ ${ }^{13,18}$ Therefore, further studies should assess the generalizability of current results to other cultural environments, and identify which psychological variables influence the prognosis of LBP in the Spanish cultural context. Those studies should be longitudinal, include large representative samples of acute and chronic patients recruited in clinical practice and use non-hierarchical models, in order to be comparable with the current one and to lead to results which are potentially relevant to clinical practice.

According to the results of this study, a high baseline score for catastrophizing does not predict the clinical course of pain or disability (Tables 3 and 4), whereas improvement in pain is associated with a higher OR for improvement in catastrophizing (Table 5). This might be interpreted as suggesting that it is more likely that a high score in catastrophizing follows lack of improvement in pain, than that a high baseline catastrophizing score hinders improvement in pain or disability. This interpretation would contribute to the "chicken and egg dilemma" debate with regards to the potential reciprocal influence between catastrophizing and lack of clinical improvement., 
The strengths of this study include its large sample, the low number of exclusions, losses to follow-up and missing data, and generalizability of its results to routine clinical practice. Weaknesses are its observational design, relatively short follow-up, that catastrophizing was the only psychological variable assessed, that continuous variables had to be dichotomized at the analysis stage, and the lack of evidence on the size of the minimal clinically important change (MCIC) for catastrophizing. These potential limitations are discussed in the following paragraphs.

Some patients included in this study showed high levels of catastrophizing and low levels of pain and disability at baseline, while others showed the opposite (Tables 1 and 2). The large sample size and the absence of losses to follow-up, allowed the identification of sizeable subgroups comprising those in whom each variable improved and did not improve throughout the study period. This allowed this study to assess the prognostic value of baseline catastrophizing for predicting the evolution of pain and disability, despite its observational design.

Chronic patients generate most of the social and economic burden associated with LBP. 57,58 Therefore, in this study follow-up was planned at 3 months to ensure that all patients who were still symptomatic at the follow-up assessment would be chronic, ${ }^{45}$ and to minimize the risk of losses associated with longer follow-up periods within the routine clinical practice of the SNHS. ${ }^{36}$ However, since baseline catastrophizing does not predict the clinical evolution of pain or disability during the first three months, it is not likely for it to become relevant at a later stage. In fact, the prognosis of chronic low back pain is determined by changes in pain and disability occurring in the initial period. ${ }^{59}$

Catastrophizing might influence other psychological variables which have not been assessed in this study and which may influence patients' general health and well being, such as fear, anxiety or depression. ${ }^{20,21,52,53,60-62}$ Therefore, although catastrophizing score cannot be used to identify those patients in whom LBP has a worse prognosis, it may still be useful to identify those subjects with underlying emotional or psychological comorbidities. Further studies should compare the validity, reliability and feasibility of measuring catastrophizing or other psychological variables (e.g., anxiety or depression) to identify these patients in routine practice. On the other hand, results from this study show that the improvement of pain is associated with the improvement of catastrophizing, suggesting that successfully treating pain might be an effective way of improving catastrophizing and other potentially related psychological variables. Further studies should test this hypothesis.

Continuous variables had to be dichotomized into categories for logistic regression analyses. This might have led to a loss of statistical power. Anticipating this, a large sample was established at the design phase, and measures to reduce missing data and losses to follow-up were planned and successfully implemented. In fact, statistical power was enough to show that pain improvement is associated with the evolution of catastrophizing (Table 5).

Previous studies have shown that the cut-off point to consider a change in pain as "clinically relevant", corresponds to $30 \%$ of its baseline value, and that the same criterion is valid for disability. ${ }^{37,44}$ Therefore, at the design phase of this study it was decided to establish the same cut-off point for catastrophizing. It was also decided to perform a 
sensitivity analysis in which "any positive change"-regardless of its size- would be considered as clinically relevant. Results from analyses using both cut-off points are consistent, which suggests that the lack of previous evidence on the MCIC for catastrophizing does not challenge the validity of results from this study (Table 5).

In conclusion, this study shows that, in routine clinical practice, assessing baseline catastrophizing does not help clinicians to predict the evolution of LBP and disability at 3 months. 


\section{References}

1. Waddell G, The Back Pain Revolution, ed 2. Churchill-Livingstone, London 2004.

2. Burton AK, Tillotson KM, Main CJ, Hollis S. Psychosocial predictors of outcome in acute and subchronic low back trouble. Spine 1995;20:722-8.

3. Linton SJ. A review of psychological risk factors in back and neck pain. Spine 2000;25:1148-1156

4. Picavet HS, Vlaeyen JWS, Schouten JS. Pain catastrophizing and kinesiophobia: predictors of chronic low back pain. Am J Epidemiol 2002;156:1028-1034

5. Pincus T, Burton AK, Vogel S, Field AP. A systematic review of psychological factors as predictors of chronicity/disability in prospective cohorts of low back pain. Spine 2002;27:E109-E120.

6. Sullivan MJ, Thorn B, Haythornthwaite JA, Keefe F, Martin M, Bradley LA, Lefebvre JC. Theoretical perspectives on the relation between catastrophizing and pain. Clin J Pain 2001;17:52-64.

7. Linton SJ, Buer N, Vlaeyen J, Hellsing AL. Are fear-avoidance beliefs related to a new episode of back pain? A prospective study. Psychol Health 1999;14:1051-9.

8. Turk DC. Biopsychosocial perspective on chronic pain. In: Gatchel RJ, Turk DC, eds. Psychological Approaches to Pain Management: A Practitioner's Handbook. Vol 1. New York: Guilford Press, 1996.

9. Weiser S, Cedraschi C. Psychosocial issues in the prevention of chronic low back pain: A literature review. Baillieres Clin Rheumatol 1992;6:657-84.

10. Kovacs FM, Muriel A, Abraira V, et al. The influence of fear avoidance beliefs on disability and quality of life is sparse in Spanish low back pain patients. Spine 2005;30:E676-E682

11. Kovacs F, Abraira V, Cano A, Royuela A, Gil del Real MT, Gestoso M, Mufraggi N, Muriel A, Zamora J, Spanish Back Pain Research Network. Fear Avoidance Beliefs do not influence disability and quality of life in Spanish elderly subjects with low back pain. Spine 2007;32:2133-2138.

12. Kovacs F, Abraira V, Santos S, et al. A Comparison of Two Short Education Programs for Improving Low Back Pain-Related Disability in the Elderly. A Cluster Randomized Controlled Trial. Spine 2007;32:1053-1059

13. Kovacs FM, Noguera J, Abraira V, Royuela A, Cano A, Gil del Real MT, Zamora J, Gestoso M, Muriel A, Mufraggi N. The influence of psychological factors on low back pain-related disability in community-dwelling older persons. Pain Med 2008;9(7):871-880.

14. Kovacs FM, Seco J, Royuela A, Peña A, Muriel A and the Spanish Back Pain Research Network. The correlation between pain, catastrophizing and disability in subacute and chronic low back pain. A study in the routine clinical practice of the Spanish National Health Service. Spine 2011;36:339-345.

15. Buer N, Linton SJ. Fear-avoidance beliefs and catastrophizing: occurrence and risk factor in back pain and ADL in the general population. Pain. 2002;99(3):485-91.

16. Peters ML, Vlaeyen JW, Weber WE. The joint contribution of physical pathology, pain-related fear and catastrophizing to chronic back pain disability. Pain 2005;113(12):40-45.

17. Swinkels-Meewisse IE, Roelofs J, Oostendorp RA, Verbeek AL, Vlaeyen JW. Acute low back pain: pain-related fear and pain catastrophizing influence physical performance and perceived disability. Pain 2006;120(1-2):36-43 
18. Woby SR, Watson PJ, Roach NK, Urmston M. Adjustment to chronic low back pain. The relative influence of fear-avoidance beliefs, catastrophizing, and appraisals of control. Behav Res Ther 2004;42(7):761-4

19. Albadalejo C, Kovacs FM, Royuela A, del Pino R, Zamora J et al. The efficacy of a short education program and a short physiotherapy program for treating low back pain in primary care. A cluster randomized trial. Spine 2010;35:483-496

20. Smeets RJ, Vlaeyen J, Kester AD, Knottnerus JA. Reduction of pain catastrophizing mediates the outcome of both physical and cognitive-behavioral treatment in chronic low back pain. J Pain 2006;7(4):261-71

21. Spinhoven P, Ter Kuile M, Kole-Snijders AM, Hutten Mansfeld M, Den Ouden DJ, Vlaeyen JW. Catastrophizing and internal pain control as mediators of outcome in the multidisciplinary treatment of chronic low back pain. Eur J Pain 2004;8(3):211-9

22. George SZ, Zeppieri G, Cere AL, Cere MR, Borut MS, Hodges MJ, Reed DM, Valencia C, Robinson ME. A randomized trial of behavioral physical therapy interventions for acute and subacute low back pain. Pain 2008;14:145-157.

23. Hirsh AT, George SZ, Riley JL, 3rd, Robinson ME. An evaluation of the measurement of pain catastrophizing by the coping strategies questionnaire. Eur J Pain 2007;11(1):75-81.

24. Philips HC, Grant L. The evolution of chronic back pain problems. Behav Res Ther 1991;29:435-41.

25. Potter RG, Jones JM. The evolution of chronic pain among patients with musculoskeletal problems: A pilot study in primary care. Br J Gen Pract 1992;42:462-4

26. Severeijns R, Vlaeyen J, van den Hout MA, Weber WE. Pain catastrophizing predicts pain intensity, disability, and psychological distress independent of the level of physical impairment. Clin J Pain 2001;17(2):165-72

27. Smeets RJ, Maher CG, Nicholas MK, Refshauge KM, Herbert RD. Do psychological characteristics predict response to exercise and advice for subacute low back pain? Arthritis Rheum. 2009 Sep 15;61(9):1202-9

28. Truchon M, Côté D. Predictive validity of the Chronic Pain Coping Inventory in subacute low back pain. Pain. 2005 Aug;116(3):205-12

29. Wand BM, McAuley JH, Marston L, De Souza LH. Predicting outcome in acute low back pain using different models of patient profiling. Spine 2009;34(18):1970-5.

30. Woby SR, Watson PJ, Roach NK, Urmston M. Are changes in fear-avoidance beliefs, catastrophizing, and appraisals of control, predictive of changes in chronic low back pain and disability? Eur J Pain 2004;8(3):201-10.

31. Woby SR, Watson PJ, Roach NK, Urmston M. Coping strategy use: does it predict adjustment to chronic back pain after controlling for catastrophic thinking and selfefficacy for pain control? J Rehabil Med 2005;37(2):100-7.

32. Foster NE, Thomas E, Bishop A, Dunn KM, Main CJ. Distinctiveness of psychological obstacles to recovery in low back pain patients in primary care. Pain 2010;148:398-406

33. Deyo RA, Rainville J, Kent DL. What can the history and physical examination tell us about low back pain? JAMA 1992;268(6):760-5

34. Slipman CW, Patel RK, Botwin K, Huston C, Zhang L, Lenrow D, Garvan C Epidemiology of spine tumors presenting to musculoskeletal physiatrists. Arch Phys Med Rehabil 2003;84(4): 492-5

35. van den Hoogen HMM, Koes BW, van Eijk JThM, Bouter LM. On the accuracy of history, physical examination and erythrocyte sedimentation rate in diagnosing low 
back pain in general practice. A criteria-based review of the literature. Spine 1995; 20: 318-27.

36. Kovacs FM, Fernandez C, Cordero A, Muriel A, González-Luján L and the Spanish Back Pain Research Network. Non-specific low back pain in primary care in the Spanish National Health Service: a prospective study on clinical outcomes and determinants of management. Biomed Central Health Serv Res 2006 URL: http://www.biomedcentral.com/1472-6963/6/57

37. Kovacs FM, Abraira V, Royuela A, Corcoll J, Alegre L, Cano A, Muriel A, Zamora J, Gil del Real MT, Gestoso M, Mufraggi N, Spanish Back Pain Research Network. Minimal clinically important change for pain intensity and disability in patients with nonspecific low back pain. Spine 2007;32:2915-2920

38. Kovacs FM, Abraira V, Zamora J, Fernández C, and the Spanish Back Pain Research Network. The transition from acute to subacute chronic low back pain. A Study based on determinants of quality of life and prediction of chronic disability. Spine 2005; 30: 1786-92.

39. Harrell FE. Multivariable Modeling Strategies. In: Springer, editor. Regression Modeling Strategies. New York: 2002. 60-61.

40. Deyo RA, Battie M, Beurskens AJ, Bombardier C, Croft P, Koes B, Malmivaara A, Roland M, Von Korff M, Waddell G. Outcome measures for low back pain research. A proposal for standardized use. Spine 1998;23(18):2003-13.

41. Huskinson EC. Measurement of pain. Lancet 1974; 2: 1127-1131

42. Kovacs FM, Llobera J, Gil del Real MT, et al. Validation of the Spanish version of the Roland Morris Questionnaire. Spine 2002; 27 (5): 538-542

43. Rodríguez L, Cano FJ, Blanco A. Evaluación de las estrategias de afrontamiento del dolor crónico. Actas Esp Psiquiatr 2004; 32(2):82-91

44. Ostelo RW, Deyo RA, Stratford P, Waddell G, Croft P, Von Korff M, Bouter LM, de Vet HC. Interpreting change scores for pain and functional status in low back pain: towards international consensus regarding minimal important change. Spine 2008;33(1):90-4.

45. Merskey H, Bogduk N. Description of chronic pain syndromes and definitions of pain terms. In: Classification of Chronic Pain, 2nd ed. Seattle: IASP Press, 1994. 39-58

46. Kleinbaum DG, Kupper LL, Morgenstern H. Epidemiologic Research: Principles and Quantitative Methods. New York: Van Nostrand Reinhold; 1982.

47. Kleinbaum DG, Kupper LL, Muller KE. Applied Regression Analysis and Other Multivariable Methods, 2nd ed. Boston: PWS-Kent; 1988.

48. Altman DG, Royston P. The cost of dichotomising continuous variables. BMJ 2006; 332(7549):1080.

49. Belsley DA. Conditioning Diagnostics: Collinearity and Weak Data in Regression. New York: John Wiley \& Sons, 1991.

50. Moix J, Kovacs FM, Martín A, Plana MN, Royuela A, and the Spanish Back Pain Research Network. Catastrophizing, state-anxiety, anger and depressive symptoms do not correlate with disability when variations of trait-anxiety are taken into account. A study of chronic low back pain patients treated in Spanish pain units [NCT00360802]. Pain Med 2011;12:1008-1017

51. van Tulder M, Becker A, Bekkering T, Breen A, Gil del Real MT, Hutchinson A, Koes B, Laerum E, Malmivaara A, On behalf of the COST B13 Working Group on Guidelines for the Management of Acute Low Back Pain in Primary Care. European guidelines for the management of acute nonspecific low back pain in primary care. Eur Spine J 2006;15:S169-191. 
52. Airaksinen O, Brox JI, Cedraschi C, Hildebrandt J, Klaber-Moffett J, Kovacs FM, Mannion AF, Reis S, Staal JB, Ursin H, Zanoli G, On behalf of the COST B13 Working Group on Guidelines for Chronic Low Back Pain. European guidelines for the management of chronic nonspecific low back pain. Eur Spine J 2006;15:S192-300

53. Leeuw M, Goossens ME, Linton SJ, et al. The fear-avoidance model of musculoskeletal pain: current state of scientific evidence. J Behav Med 2007;30(1):77-94

54. Rosenstiel AK, Keefe FJ. The use of coping strategies in chronic low back pain patients: relationship to patient characteristics and current adjustment. Pain 1983; 17:33-44.

55. Elfving B, Andersson T, Grooten WJ. Low levels of physical activity in back pain patients are associated with high levels of fear-avoidance beliefs and pain catastrophizing. Physiother Res Int 2007;12(1):14-24

56. Linton SJ. The role of psychological factors in back pain and its remediation. Pain Reviews 1994;1:231-43.

57. Andersson GBJ. Epidemiologic features of chronic low-back pain. Lancet 1999; 354: 581-585.

58. van Tulder MW, Koes BW, Bouter LM. A cost-of-illness study of back pain in The Netherlands. Pain 1995, 62:233-240.

59. Heymans MW, van Buuren S, Knol DL, Anema JR, van Mechelen W, de Vet HCW. The prognosis of chronic low back pain is determined by changes in pain and disability in the initial period. Spine J 2010;10:847-856

60. Turner JA, Holtzman S, Mancl L. Mediators, moderators, and predictors of therapeutic change in cognitive-behavioral therapy for chronic pain. Pain 2007;127(3):276-86

61. Vlaeyen JW, Linton SJ. Fear-avoidance and its consequences in chronic musculoskeletal pain: a state of the art. Pain 2000;85(3):317-32

62. McCracken LM, Gross RT. Does anxiety affect coping with chronic pain? Clin J Pain 1993;9(4):253-9. 
Table 1. Baseline characteristics of patients included in the study

\begin{tabular}{|c|c|}
\hline Variables & All patients $(n=1422)$ \\
\hline Gender (males) * & $532(37.4)$ \\
\hline Age (years) $a$ & $52.6(15.0)$ \\
\hline Eligible for workers' compensation & $824(58.0)$ \\
\hline \multicolumn{2}{|l|}{ Duration of pain * } \\
\hline Acute $(<14$ days) & $113(7.9)$ \\
\hline Subacute (14-90 days) & 479 (33.7) \\
\hline \multicolumn{2}{|l|}{ Chronic: } \\
\hline 91-365 days & $553(38.9)$ \\
\hline > 365 days & 277 (19.5) \\
\hline Failed back syndrome * & $21(1.5)$ \\
\hline \multicolumn{2}{|l|}{ Findings on imaging tests * } \\
\hline No findings & 255 (17.9) \\
\hline Disc degeneration & $890(62.6)$ \\
\hline Spondylolisthesis/spondylolysis & $91(6.4)$ \\
\hline Spinal stenosis & $118(8.3)$ \\
\hline Disc protrusion/herniation & 485 (34.1) \\
\hline Annular tear & $3(0.2)$ \\
\hline$>1 \mathrm{~cm}$ difference in leg length & $12(0.8)$ \\
\hline Lumbarization of S1 & $14(1.0)$ \\
\hline Sacralization of L5 & $9(0.6)$ \\
\hline Other radiological findings & $15(1.1)$ \\
\hline \multicolumn{2}{|l|}{ Diagnostic procedures * } \\
\hline X-Rays & $359(25.2)$ \\
\hline Magnetic Resonance & $355(25.0)$ \\
\hline CT-scan & $50(3.5)$ \\
\hline Electromiography & $58(4.1)$ \\
\hline Blood analysis & $53(3.7)$ \\
\hline Scintigraphy & $3(0.2)$ \\
\hline \multicolumn{2}{|l|}{ Drug treatment * } \\
\hline NSAIDs & $806(56.7)$ \\
\hline Corticoids & $96(6.8)$ \\
\hline Muscle relaxants & $274(19.3)$ \\
\hline Other & $139(9.8)$ \\
\hline Physiotherapy or rehabilitation * & $176(12.4)$ \\
\hline Neuro-reflexotherapy * & $1242(87.3)$ \\
\hline Surgery * & $8(0.6)$ \\
\hline Other treatments* & $15(1.1)$ \\
\hline LBP (VAS) a & $6.7(2.1)$ \\
\hline LP (VAS) $(n=1098) a$ & $6.2(2.4)$ \\
\hline Disability (RMQ) a & $12.8(5.6)$ \\
\hline Catastrophizing (CSQ) a & $15.0(8.5)$ \\
\hline
\end{tabular}

* Frequency (\%) a Mean (SD) LBP: Severity of low back pain LP: Severity of referred pain down into the leg (leg pain) (in the 1098 patients who had it) RMQ: Score in the Roland-Morris Questionnaire CSQ: Score in the Coping Strategies Questionnaire 
Table 2. Baseline characteristics of patients in whom low back pain, disability and catastrophizing improved and did not improve throughout the study.

\begin{tabular}{|c|c|c|c|c|c|c|c|c|c|}
\hline Variable & $\begin{array}{c}\text { LBP improved } \\
(\mathrm{n}=1043) \dagger\end{array}$ & $\begin{array}{l}\text { LBP did not } \\
\text { improve } \\
(n=355) \dagger\end{array}$ & $p$ & $\begin{array}{l}\text { Disability } \\
\text { improved } \\
(\mathrm{n}=879) \ddagger\end{array}$ & $\begin{array}{l}\text { Disability did } \\
\text { not improve } \\
(\mathrm{n}=466) \ddagger\end{array}$ & $p$ & $\begin{array}{l}\text { Catastrophizing } \\
\text { improved } \\
\text { (n=1010) } ¥\end{array}$ & $\begin{array}{c}\text { Catastrophizing } \\
\text { did not improve } \\
(\mathrm{n}=406) ¥\end{array}$ & $\mathrm{p}$ \\
\hline Gender (males)* & $391(37.5)$ & $126(37.2)$ & 0.501 & $333(37.9)$ & $167(35.8)$ & 0.460 & $378(37.4)$ & $152(37.4)$ & 0.996 \\
\hline Age (years) a & $52(41 ; 63)$ & $52(41 ; 64)$ & 0.983 & $52(41 ; 63)$ & $53(43 ; 65)$ & 0.071 & $53(42 ; 64)$ & $50(40 ; 62)$ & 0.035 \\
\hline Eligible for workers' compensation & $598(57.3)$ & $207(58.6)$ & 0.668 & $519(59.0)$ & $255(55.0)$ & 0.149 & $585(57.9)$ & $235(58.2)$ & 0.932 \\
\hline Chronicity * & & & 0.006 & & & 0.177 & & & 0.944 \\
\hline$<14$ days & $91(8.7)$ & $18(5.1)$ & & $71(8.1)$ & $30(6.4)$ & & $82(8.1)$ & $30(7.4)$ & \\
\hline $14-90$ days & $362(34.7)$ & $105(29.6)$ & & 307 (34.9) & $143(30.7)$ & & 341 (33.8) & $137(33.7)$ & \\
\hline $91-365$ days & $403(38.6)$ & $146(41.1)$ & & 341 (38.8) & $193(41.4)$ & & $394(39.0)$ & $157(38.7)$ & \\
\hline$>365$ days & 187 (17.9) & $86(24.2)$ & & $160(18.2)$ & $100(21.5)$ & & $193(19.1)$ & $82(20.2)$ & \\
\hline Failed back surgery * & $8(0.8)$ & $13(3.7)$ & $<0.001$ & $8(0.9)$ & $13(2.8)$ & 0.008 & $8(0.8)$ & $12(3.0)$ & 0.002 \\
\hline \multicolumn{10}{|l|}{ Findings on imaging tests * } \\
\hline Disc degeneration & $662(63.5)$ & $221(62.3)$ & 0.681 & $546(62.1)$ & $314(67.4)$ & 0.056 & $651(64.5)$ & $238(58.6)$ & 0.040 \\
\hline Spondylolisthesis/spondylolysis & $71(6.8)$ & $19(5.4)$ & 0.335 & $55(6.3)$ & $33(7.1)$ & 0.561 & $63(6.2)$ & $28(6.9)$ & 0.647 \\
\hline Spinal stenosis & $79(7.6)$ & 38 (10.7) & 0.066 & $74(8.4)$ & 41 (8.8) & 0.813 & $84(8.3)$ & $34(8.4)$ & 0.972 \\
\hline Disc protrusion/hernia & 330 (31.6) & $145(40.8)$ & 0.002 & 298 (33.9) & 169 (36.3) & 0.386 & $333(33.0)$ & $151(36.9)$ & 0.130 \\
\hline Annular tear & $2(0.2)$ & $0(0)$ & 1.000 & $2(0.2)$ & $1(0.2)$ & 1.000 & $1(0.1)$ & $2(0.5)$ & 0.199 \\
\hline$>1 \mathrm{~cm}$ difference in leg length & $8(0.8)$ & $3(0.8)$ & 1.000 & $7(0.8)$ & $3(0.6)$ & 1.000 & $9(0.9)$ & $2(0.5)$ & 0.738 \\
\hline Lumbarization of S1 & $9(0.9)$ & $4(1.1)$ & 0.749 & $8(0.9)$ & $6(1.3)$ & 0.576 & $7(0.7)$ & $4(1.0)$ & 0.522 \\
\hline Sacralization of L5 & $6(0.6)$ & $2(0.6)$ & 1.000 & $4(0.5)$ & $5(1.1)$ & 0.290 & $6(0.6)$ & $2(0.5)$ & 0.818 \\
\hline No finding & $177(17.0)$ & 70 (19.7) & 0.241 & $142(16.2)$ & $88(18.9)$ & 0.026 & $160(15.8)$ & $94(23.2)$ & 0.001 \\
\hline \multicolumn{10}{|l|}{ Diagnostic procedures * } \\
\hline X-Rays & $223(21.4)$ & $127(35.8)$ & $<0.001$ & $178(20.3)$ & $157(33.7)$ & $<0.001$ & $213(21.1)$ & $141(34.7)$ & $<0.001$ \\
\hline Magnetic Resonance & 230 (22.1) & $114(32.1)$ & $<0.001$ & $206(23.4)$ & 134 (28.8) & 0.033 & $226(22.4)$ & $126(31.0)$ & $<0.001$ \\
\hline CT scan & $23(2.2)$ & $26(7.3)$ & $<0.001$ & $18(2.0)$ & $28(6.0)$ & $<0.001$ & $21(2.1)$ & $28(6.9)$ & $<0.001$ \\
\hline Electromiography & $25(2.4)$ & $28(7.9)$ & $<0.001$ & $21(2.4)$ & $32(6.9)$ & $<0.001$ & $21(2.1)$ & $35(8.6)$ & $<0.001$ \\
\hline Blood analysis & $22(2.1)$ & $28(7.9)$ & $<0.001$ & $17(1.9)$ & $31(6.7)$ & $<0.001$ & $17(1.7)$ & $34(8.4)$ & $<0.001$ \\
\hline Scintigraphy & $2(0.2)$ & $0(0)$ & 1.000 & $2(0.2)$ & $1(0.2)$ & 1.000 & $1(0.1)$ & $2(0.5)$ & 0.199 \\
\hline \multicolumn{10}{|l|}{ Drug treatment * } \\
\hline NSAIDs & $584(56.0)$ & $209(58.9)$ & 0.344 & $492(56.0)$ & $278(59.7)$ & 0.194 & $550(54.5)$ & $254(62.6)$ & 0.005 \\
\hline Corticoids & $51(4.9)$ & 41 (11.5) & $<0.001$ & $42(4.8)$ & 47 (10.1) & $<0.001$ & $44(4.4)$ & $51(12.6)$ & $<0.001$ \\
\hline Muscle relaxants & $183(17.5)$ & $84(23.7)$ & 0.011 & $169(19.2)$ & $94(20.2)$ & 0.677 & $163(16.1)$ & 109 (26.8) & $<0.001$ \\
\hline Other & $100(9.6)$ & 39 (11.0) & 0.447 & $84(9.6)$ & 54 (11.6) & 0.243 & $93(9.2)$ & 46 (11.3) & 0.225 \\
\hline Physiotherapy or rehabilitation * & $101(9.7)$ & $70(19.7)$ & $<0.001$ & $86(9.8)$ & 78 (16.7) & $<0.001$ & $92(9.1)$ & $81(20.0)$ & $<0.001$ \\
\hline Neuro-reflexotherapy * & 975 (93.5) & $258(72.7)$ & $<0.001$ & $832(94.7)$ & $365(78.3)$ & $<0.001$ & 947 (93.8) & $295(72.7)$ & $<0.001$ \\
\hline Surgery* & $3(0.3)$ & $5(1.4)$ & 0.029 & $3(0.3)$ & $5(1.1)$ & 0.134 & $2(0.2)$ & $6(1.5)$ & 0.009 \\
\hline Other treatments* & $7(0.7)$ & $6(1.7)$ & 0.106 & $5(0.6)$ & $9(1.9)$ & 0.025 & $6(0.6)$ & $9(2.2)$ & 0.017 \\
\hline Severity of LBP (VAS) a & $7(6 ; 8)$ & $6(4 ; 8)$ & $<0.001$ & $7(5 ; 8)$ & $7(5 ; 8)$ & 0.290 & $7(5 ; 8)$ & $7(5 ; 8)$ & 0.009 \\
\hline Patients with $\mathrm{LP}^{*}$ & 775 (74.4) & $247(69.6)$ & 0.078 & 647 (73.7) & $348(74.7)$ & 0.694 & 754 (74.7) & $277(78.2)$ & 0.013 \\
\hline Severity of LP (VAS)ם & $7(5 ; 8)$ & $1(0 ; .6)$ & 0.154 & $6(2 ; 8)$ & $5(2 ; 8)$ & 0.481 & $5(1 ; 8)$ & $5(2 ; 7)$ & 0.911 \\
\hline Disability (RMQ) a & $14(0 ; 18)$ & $12(8 ; 16)$ & 0.451 & $14(10 ; 18)$ & $12(8 ; 16)$ & $<0.001$ & $13(9 ; 17)$ & $13(8 ; 17)$ & 0.970 \\
\hline Catastrophizing (CSQ) a & $16(9 ; 22)$ & $13(7 ; 19)$ & 0.443 & $15(9 ; 21)$ & $14(8 ; 20)$ & 0.028 & $15(8 ; 21)$ & $14(8 ; 20)$ & $<0.001$ \\
\hline
\end{tabular}

* Frequency (\%) a Median (p25;p75) LBP: Low back pain LP: Referred pain down into the leg (in the 1098 patients who had it) RMQ: Score in the Roland-Morris Questionnaire CSQ: Score in the Coping Strategies Questionnaire † Only includes patients whose pain severity at baseline was high enough to allow for a clinically relevant improvement (i.e., baseline VAS > 1.5). $\ddagger$ Only includes patients whose disability at baseline was high enough to allow for a clinically relevant improvement (i.e., baseline RMQ > 3). ¥ Only includes patients whose catastrophizing at baseline was high enough to allow for improvement (i.e., baseline CSQ $\geq 1$ ). 
Table 3. Association between catastrophizing at baseline, and the evolution of the severity of low back pain throughout the study period (3 months).

\begin{tabular}{|c|c|c|c|c|}
\hline & \multicolumn{2}{|c|}{ Crude analysis } & \multicolumn{2}{|c|}{ Adjusted analysis** } \\
\hline & $\mathrm{OR}(\mathrm{Cl} 95 \%)$ & $\mathrm{p}$ & OR (CI 95\%) & $\mathrm{P}$ \\
\hline $\begin{array}{l}\text { Catastrophizing } \\
\text { at baseline* }\end{array}$ & & 0.253 & & 0.163 \\
\hline Q1 $(\leq 8)$ & Ref.cat & & Ref. cat & \\
\hline Q2 (9-15) & $1.42(0.99 ; 2.02)$ & 0.055 & $0.87(0.58 ; 1.31)$ & 0.509 \\
\hline Q3 (16-21) & $1.13(0.79 ; 1.61)$ & 0.502 & $0.66(0.43 ; 1.01)$ & 0.056 \\
\hline Q4 ( $\geq 22)$ & $1.28(0.88 ; 1.85)$ & 0.197 & $0.63(0.39 ; 1.02)$ & 0.060 \\
\hline
\end{tabular}

*: Categorized in quartiles.

**: Variables included in the model were: gender, age, baseline values for LBP, leg pain and LBPrelated disability, duration of the current episode (acute, subacute, chronic and extremely chronic), the interaction between baseline CSQ and chronicity, workers' compensation coverage, diagnosis of "failed back surgery", radiological findings, diagnostic procedures performed throughout the study, and treatments received. Results had to be adjusted only by baseline severity of low back pain, baseline degree of disability, and having undergone neuroreflexotherapy intervention. OR's for these variables are not shown, since they may have been confounded by unknown variables which were not controlled for. ${ }^{24}$

In the model in which prescribed treatments were removed from the models, only baseline severity of low back pain showed a confounding effect, and changes in results were minor [adjusted global p: 0.080, and adjusted OR (CI95\%) for Q2, Q3 and Q4: $1.16(0.80 ; 1.69), 0.81(0.55 ; 1.18)$ and 0.71 $(0.47 ; 1.07)$, respectively]. 
Table 4. Association between catastrophizing at baseline, and the evolution of disability throughout the study period (3 months).

\begin{tabular}{|c|c|c|c|c|}
\hline & \multicolumn{2}{|c|}{ Crude analysis } & \multicolumn{2}{|c|}{ Adjusted analysis** } \\
\hline & OR (Cl 95\%) & $p$ & OR (CI 95\%) & $\mathrm{P}$ \\
\hline $\begin{array}{l}\text { Catastrophizing } \\
\text { at baseline* }\end{array}$ & & 0.003 & & 0.167 \\
\hline Q1 $(\leq 8)$ & Ref. cat & & Ref. cat & \\
\hline Q2 (9-15) & $1.43(1.04 ; 1.97)$ & 0.028 & $0.87(0.61 ; 1.23)$ & 0.428 \\
\hline Q3 (16-20) & $1.71(1.21 ; 2.41)$ & 0.002 & $0.76(0.51 ; 1.12)$ & 0.167 \\
\hline Q4 ( $\geq 21)$ & $1.73(1.24 ; 2.40)$ & 0.001 & $0.64(0.43 ; 0.96)$ & 0.029 \\
\hline
\end{tabular}

*: Categorized in quartiles.

**: Variables included in the maximal model were: gender, age, baseline values for LBP, leg pain and LBP-related disability, duration of the current episode (acute, subacute, chronic and extremely chronic), the interaction between baseline CSQ and chronicity, workers' compensation coverage, diagnosis of "failed back surgery", radiological findings, diagnostic procedures performed throughout the study, and treatments received. Results had to be adjusted only by baseline degree of disability, and having undergone neuro-reflexotherapy intervention. OR's for these variables are not shown, since they may have been confounded by unknown variables which were not controlled for. ${ }^{24}$

In the model in which prescribed treatments were removed from the models, only baseline severity of disability showed a confounding effect, and changes in results were minor [adjusted global p: 0.459 , and adjusted OR (CI95\%) for Q2, Q3 and Q4: 1.14 (0.82;1.60), $1.01(0.70 ; 1.47)$ and 0.85 $(0.58 ; 1.25)$, respectively] 
Table 5. Association between the evolution of the severity of low back pain and the improvement of catastrophizing. $\dagger$

\begin{tabular}{|c|c|c|c|c|}
\hline & \multicolumn{2}{|c|}{ Crude analysis } & \multicolumn{2}{|c|}{ Adjusted analysis** } \\
\hline & OR (Cl 95\%) & $\mathrm{p}$ & OR (Cl 95\%) & $\mathrm{P}$ \\
\hline $\begin{array}{l}\text { Evolution of } \\
\text { severity of LBP* } \\
\text { Q1 }(\leq 1.0)\end{array}$ & Ref cat & $<0.001$ & Ref cat & $<0.001$ \\
\hline Q2 (1.1-4.0) & $4.97(3.54 ; 6.97)$ & $<0.001$ & $3.00(2.00 ; 4.50)$ & $<0.001$ \\
\hline Q3 (4.1-6.0) & $10.61(6.92 ; 16.27)$ & $<0.001$ & $3.18(1.91 ; 5.29)$ & $<0.001$ \\
\hline Q4 ( $\geq 6.1)$ & 35.87 (18.65; 68.98) & $<0.001$ & $7.32(3.49 ; 15.36)$ & $<0.001$ \\
\hline
\end{tabular}

*: Categorized in quartiles. The evolution of LBP was defined as the baseline score minus the final one, so that positive values reflect improvement.

**: Variables included in the maximal model were: gender, age, baseline values for LBP, leg pain and LBP-related disability, duration of the current episode (acute, subacute, chronic and extremely chronic), the interaction between baseline CSQ and chronicity, workers' compensation coverage, diagnosis of "failed back surgery", radiological findings, diagnostic procedures performed throughout the study, treatments received, the evolution of referred pain and the evolution of disability. Results had to be adjusted only by baseline degree of disability, improvement in disability throughout the study period, and having undergone neuroreflexotherapy intervention. OR's for these variables are not shown, since they may have been confounded by variables which were not controlled for. ${ }^{24}$

† Defining "improvement" as any reduction in the CSQ score being $\geq 30 \%$ of its baseline value. In the sensitivity analyses in which "improvement" was defined as "any reduction in the CSQ score" regardless of its size-, results had to be adjusted only by improvement in disability throughout the study period and adjusted ORs (CI 95\%) for Q2, Q3 and Q4 were: 2.87 (1.91;4.32), 4.04 $(2.28 ; 7.16)$ and $5.49(2.46 ; 12.24)$, respectively.

In the model in which prescribed treatments were removed from the models, only baseline degree of disability and improvement in disability throughout the study period showed a confounding effect, and changes in results were minor [adjusted global p: $<0.001$, and adjusted OR (CI95\%) for Q2, Q3 and Q4: 3.43 (2.30;5.10), $4.06(2.48 ; 6.66)$ and 9.58 (4.62;19.84), respectively] 